\title{
Prevalência de enteroparasitas em horticultores e hortaliças da Feira do Produtor de Maringá, Paraná
}

\author{
Prevalence of intestinal parasites in horticulturists and vegetables \\ from Feira do Produtor de Maringá, Paraná, Brazil \\ Ana Lucia Falavigna Guilherme, Silvana Marques de Araújo, Dina Lúcia Morais \\ Falavigna, Áurea Regina Teles Pupulim, Maria Luiza G. Goulart Dias, Henrique \\ Sérgio de Oliveira, Elisângela Maroco e Yoshiaki Fukushigue
}

\begin{abstract}
Resumo Poucos trabalhos têm avaliado a contaminação de hortaliças nos locais de produção, no Brasil. De abril de 1996 a dezembro de 1997, investigou-se as condições sanitárias de hortaliças consumidas cruas, vendidas na Feira do Produtor de Maringá. Para isso, analisouse a contaminação de hortaliças, de produtores (fezes e depósito subungueal) e da água utilizada na irrigação. Observou-se que 16,6\% das 144 amostras de cinco diferentes hortaliças estavam contaminadas por enteroparasitas. De 163 indivíduos analisados, 43 (26\%) apresentaram um ou mais parasitas. Só 3 depósitos subungueais foram positivos para enteroparasitas entre os 49 analisados. O resultado da análise de amostras de água utilizadas na irrigação das hortaliças não satisfez os padrões bacteriológicos de potabilidade. Conclui-se que, na região investigada, a contaminação de hortaliças se deu na fase de produção e que é necessário uma campanha de esclarecimento aos produtores.
\end{abstract}

Palavras-chaves: Enteroparasitas. Hortaliças. Produtores. Depósito subungueal.

\begin{abstract}
Few studies have assessed the contamination of vegetables at Brazilian production sites. From April 1996 to December of 1997, the sanitary conditions of raw consumed vegetables sold in the Feira do Produtor de Maringá were investigated. We based the analyses on the contamination of vegetables, of the producers (stool samples and material under the fingernails) and of the water used for irrigation. It was observed that $16.6 \%$ of 144 samples of five different types of vegetables were contaminated with intestinal parasites. Forty three of 163 individuals (26\%) were infected with one or more parasites. Only three of the 49 samples of material under the fingernails analyzed were positive for intestinal parasites. Analysis of samples of the water used for vegetable irrigation showed that the water did not satisfy bacteriological standards of potability. We conclude that in the investigated area the contamination of vegetables occurred during the production phase and that a sanitary education campaign directed at the producers is needed.
\end{abstract}

Key-words: Intestinal parasites. Vegetables. Vegetable producers. Deposit under the fingernails.

Setor de Parasitologia Básica da Universidade Estadual de Maringá, Maringá, PR.

Endereço para correspondência: Dra. Ana Lucia Falavigna Guilherme. Depto de Análises/UEM Av. Colombo 5790, zona 07, 87020-900 Maringá, PR, Brasil.

Fax: 5544 261-4490

Recebido para publicação em 12/8/98. 
O diagnóstico laboratorial de protozoários e helmintos parasitas de humanos em hortaliças é de grande importância para a saúde pública uma vez que fornece dados sobre as condições higiênicas envolvidas na produção, armazenamento, transporte e manuseio desses produtos 4 .

Vários autores brasileiros mencionam a possibilidade de transmissão de parasitoses ao homem através da ingestão de frutas e verduras consumidas cruas provenientes de áreas cultivadas e contaminadas por dejetos fecais 4910 16. Entretanto, estes não correlacionam parasitoses de produtores com as de hortaliças, assim como não verificam a potabilidade da áqua utilizada na irrigação, que constituem o objetivo da presente publicação.

\section{MATERIAL E MÉTODOS}

O presente trabalho foi desenvolvido no período de abril de 1996 a dezembro de 1997, e abrangeu todas as barracas da Feira do Produtor de Maringá que comercializavam verduras consumidas cruas. Estas verduras são produzidas em sítios estabelecidos na periferia dos municípios de Maringá, Sarandi, Paiçandu e Mandaguari. O tipo de solo predominante é latossolo roxo e terra roxa estruturada. O clima é subtropical úmido com preciptações médias anuais entre $1250 \mathrm{~mm}$ e $1500 \mathrm{~mm}$. Esta feira acontece duas vezes por semana, em região central da cidade de Maringá, PR, no horário compreendido entre 18:00 e 22:00 horas na quarta feira e de 6:00 às 11:00h no sábado. A Feira existe há onze anos e conta com - apoio da Empresa de Assistência Técnica e Extensão Rural do Paraná (EMATER). Os produtores estão vinculados a um sindicato que se reúne uma vez por mês para tomar decisões.

Com exceção da água, a coleta dos materiais biológicos foi feita durante a realização da feira.

Coletas de amostras de hortaliças, fezes, depósito subungueal e água. Hortaliças. Foram avaliadas: alface (Lactuca sativa) variedades lisa, crespa e mimosa, escarola (Chicorium sp), agrião (Nasturtium officinale), rúcula (Eruca sativa), almeirão (Chicorium intybus), salsinha (Petroselinum sativa) e cebolinha (Allium fistolosus). As amostras de hortaliças foram coletadas aleatoriamente em duplicata do total a ser comercializado no dia, por barraca, minutos antes de iniciar a venda.

Fezes. As amostras de fezes de 163 indivíduos envolvidos na produção das verduras (produtor, familiares e funcionários) foram coletadas em frascos de polietileno descartáveis. Inicialmente os participantes do projeto passavam em cada barraca e entregavam frascos e faziam esclarecimentos quanto aos procedimentos de coleta e armazenamento do material biológico. Na semana seguinte os frascos eram recolhidos e levadas ao Laboratório de Parasitologia Básica da Universidade Estadual de Maringá (UEM) para serem analisadas.
Depósito subungueal. todas as unhas da mão dos indivíduos envolvidos na horticultura, que aceitaram submeter-se ao teste, foram cortadas com tesoura, sem aviso prévio. O material foi recolhido em frascos estéreis, com formol a $10 \%$, identificado e trazido ao laboratório de Parasitologia Básica da UEM para análise.

Água. Foram coletadas amostras $(100 \mathrm{ml}) \mathrm{de}$ água usada na irrigação das hortaliças em frascos estéreis seguindo normas prescritas pelo Laboratório de Análise de Água - Setor de Microbiologia Básica/UEM. A coleta foi feita por pessoal técnico envolvido no projeto priorizando os locais que estavam com verduras contaminadas.

Acondicionamento e estocagem das amostras. As hortaliças foram acondicionadas individualmente em sacos de polietileno descartáveis, limpos e desinfectados e enviados ao laboratório de Parasitologia Básica da UEM. Para a alface e a escarola foram coletados pés inteiros e para os demais vegetais foram coletados maços.

As fezes foram conservadas em geladeira por, no máximo, 14 horas e os frascos com depósito subungueal foram armazenados à temperatura ambiente.

As amostras de água coletadas foram encaminhadas imediatamente ao Laboratório de Análise de Água /Microbiologia Básica/ UEM.

Análise das amostras. No laboratório, utilizando luvas cirúrgicas, as amostras de hortaliças foram preparadas separando folha por folha, desprezando-se as deterioradas e os talos de cada vegetal. Para a lavagem utilizou-se uma solução detergente neutro ( $10 \mathrm{ml}$ de Extram MA02 diluídos em $2000 \mathrm{ml}$ de solução salina). Com auxílio de um pincel, as folhas foram lavadas de acordo com a técnica descrita por Oliveira e Germano11. A seguir, o líquido de lavagem foi 
filtrado em gaze e deixado sedimentar por 24 horas em cálice cônico. Para verificar a presença de cistos de protozoários, o sedimento foi analisado através do método de Faust et al, apud Pessôa e Martins ${ }^{12}$, em triplicata. Para observar a presença de ovos ou larvas de helmintos utilizou-se a sedimentação em água, sendo analisadas três lâminas para cada amostra.

Os exames parasitológicos de fezes foram qualitativos, utilizando-se a técnica de Faust et al, sedimentação em água, Kato-Katz e método de Willis modificado com sulfato de zinco densidade de 1.18012. Procurou-se repetir o exame parasitológico de fezes entre os produtores que tiveram as hortaliças contaminadas.

O depósito subungueal foi analisado pelo método de Mello et al8.

A água foi analisada pela contagem do número mais provável de coliformes totais e coliformes fecais pelo método dos tubos múltiplos ${ }^{1}$, determinando sua potabilidade.

Análise dos resultados. A análise estatística foi feita utilizando o método da diferença de duas proporções independentes e o teste de Qui-quadrado com nível de significância de 5\%.

\section{RESULTADOS}

De 130 barracas presentes na feira, 39 comercializavam hortaliças consumidas cruas, sendo que 10 destas apresentaram uma ou mais hortaliças contaminadas. Analisou-se 144 amostras de hortaliças encontrando-se uma taxa de contaminação de 16,6\% (24 amostras). O agrião foi o mais contaminado (100\%), seguido de alface mimosa (25\%), alface lisa $(21,4 \%)$, rúcula $(21,4 \%)$, escarola $(9,0 \%)$, alface crespa $(6,6 \%)$. O almeirão, a cebolinha e a salsinha não apresentaram nenhuma amostra contaminada (Tabela 1). Para a alface mimosa, alface lisa, alface crespa, rúcula e escarola não houve diferença estatística significativa entre estes percentuais quando comparados pelo teste da diferença de duas proporções de amostras independentes.

Tabela 1- Hortaliças provenientes da Feira do Produtor Maringá-PR submetidas à análise parasitológica no período compreendido entre 1996 a 1997.

\begin{tabular}{|c|c|c|c|}
\hline \multirow[b]{2}{*}{ Hortaliça } & \multicolumn{2}{|c|}{ Amostras } & \multirow[b]{2}{*}{ Parasita } \\
\hline & $\begin{array}{c}\text { Analisadas } \\
n^{0}\end{array}$ & $\begin{array}{c}\text { Positivas } \\
\mathrm{n} \% \%\end{array}$ & \\
\hline Alface lisa & 28 & $6 / 21,4$ & $\begin{array}{l}\text { Entamoeba coli } \\
\text { Endolimax nana } \\
\text { Strongyloides sp } \\
\text { ancilostomídeos }\end{array}$ \\
\hline Alface crespa & 30 & $2 / 6,6$ & $\begin{array}{l}\text { Entamoeba coli } \\
\text { Strongyloides sp } \\
\text { ancilostomídeos }\end{array}$ \\
\hline Alface mimosa & 8 & $2 / 25,0$ & $\begin{array}{l}\text { Entamoeba coli } \\
\text { ancilostomídeos } \\
\text { Strongyloides } s p\end{array}$ \\
\hline Rúcula & 28 & $6 / 21,4$ & $\begin{array}{l}\text { Entamoeba coli } \\
\text { Strongyloides sp } \\
\text { Trichuris trichiura }\end{array}$ \\
\hline Escarola & 22 & $2 / 9,0$ & $\begin{array}{l}\text { Entamoeba coli } \\
\text { ancilostomídeos }\end{array}$ \\
\hline Agrião & 6 & $6 / 100$ & $\begin{array}{l}\text { Entamoeba coli } \\
\text { Strongyloides sp } \\
\text { Ascaris sp } \\
\text { Toxocara sp } \\
\text { Entamoeba sp (4N) } \\
\text { ancilostomídeos }\end{array}$ \\
\hline Almeirão & 8 & $0 / 0,0$ & negativo \\
\hline Cebolinha & 4 & $0 / 0,0$ & negativo \\
\hline Salsinha & 10 & $0 / 0,0$ & negativo \\
\hline Total & 144 & $24 / 16,6$ & \\
\hline
\end{tabular}


Foram analisados 277 exames de fezes de 163 indivíduos, sendo que 43 (26,4\%) pacientes apresentaram uma ou mais espécies de parasitas, com a seguinte prevalência: ancilostomídeos $(37,8 \%)$, Entamoeba coli $(28,9 \%)$, Endolimax nana $(22,2 \%)$, Giardia lamblia (11,1\%), Entamoeba histolytica (4,4\%), Hymenolepis nana $(4,4 \%)$, lodamoeba butschillii (4,4\%), Trichuris trichiura $(4,4 \%)$, Strongyloides stercoralis $(4,4 \%)$, Schistosoma mansoni (4,4\%), e Ascaris lumbricoides $(2,2 \%)$. Os casos positivos foram encaminhados à Secretaria de Saúde do Município de Maringá e tratados especificamente.

O exame parasitológico do depósito subungueal foi realizado em 49 indivíduos, sendo que só três deles, de barracas distintas, apresentaram-se positivos para Entamoeba coli.

De 39 barracas investigadas, foram encontrados indivíduos positivos (fezes ou depósito subungueal) em 13, embora as verduras não estivessem contaminadas. Em uma barraca foi encontrada hortaliça contaminada mas os indivíduos estavam negativos. Em nove barracas observou-se que havia indivíduos e verduras contaminadas. Entretanto, somente em cinco delas houve concordância entre os parasitas encontrados nas hortaliças e em seus produtores (Tabela 2).

Pelo teste do qui-quadrado, não houve predomíneo de Strongyloides sp, ancilostomídeos

Tabela 2 - Resultado de barracas que apresentaram hortaliças e fezes contaminadas (1996-1997).

\begin{tabular}{|c|c|c|c|}
\hline $\begin{array}{l}\text { Número da } \\
\text { barraca }\end{array}$ & $\begin{array}{l}\text { Variedade } \\
\text { de hortaliça }\end{array}$ & $\begin{array}{c}\text { Resultado da análise } \\
\text { da hortaliça }\end{array}$ & $\begin{array}{c}\text { Resultado do parasitológico } \\
\text { de fezes }\end{array}$ \\
\hline \multirow[t]{2}{*}{2} & alface lisa & ancilostomídeos & ancilostomídeos \\
\hline & & Strongyloides sp & \\
\hline \multirow[t]{5}{*}{41} & escarola & Entamoeba coli & Giardia lamblia \\
\hline & alface mimosa & ancilostomídeos & ancilostomídeos \\
\hline & alface crespa & ancilostomídeos & Entamoeba coli \\
\hline & alface lisa & Negativa & \\
\hline & rúcula & Negativa & \\
\hline \multirow[t]{3}{*}{61} & rúcula & Trichuris $s p$ & Entamoeba coli \\
\hline & alface lisa & Entamoeba coli & ancilostomídeos \\
\hline & escarola & ancilostomídeos & Trichuris trichiura \\
\hline 64 & alface lisa & Entamoeba coli & Entamoeba coli \\
\hline \multirow[t]{3}{*}{67} & agrião & Entamoeba coli & Entamoeba coli \\
\hline & & Entamoeba sp (4N) & Endolimax nana \\
\hline & & Strongyloides sp & \\
\hline \multirow[t]{5}{*}{88} & agrião & Strongyloides sp & Entamoeba coli \\
\hline & & Toxocara sp & Endolimax nana \\
\hline & & & S. mansoni \\
\hline & & & ancilostomídeos \\
\hline & & & Strongyloides sp \\
\hline \multirow[t]{3}{*}{96} & agrião & Strongyloides sp & Entamoeba coli \\
\hline & & ancilostomídeos & \\
\hline & & Ascaris sp & \\
\hline \multirow[t]{8}{*}{102} & alface lisa & Endolimax nana & Giardia lamblia \\
\hline & & Strongyloides sp & A. lumbricoides \\
\hline & alface crespa & Entamoeba coli & \\
\hline & & Strongyloides sp & \\
\hline & alface mimosa & Entamoeba coli & \\
\hline & & Strongyloides sp & \\
\hline & rúcula & Entamoeba coli & \\
\hline & & Strongyloides sp & \\
\hline \multirow[t]{4}{*}{114} & rúcula & Entamoeba coli & Endolimax nana, \\
\hline & & & Hymenolepis nana \\
\hline & & & ancilostomídeos \\
\hline & & & Entamoeba histolytica \\
\hline
\end{tabular}


e Entamoeba coli em relação às hortaliças estudadas $\left(\chi^{2}=2,00 ; p=0,7358 ; \chi^{2}=0,972\right.$; $\left.\mathrm{p}=0,9648 ; \chi^{2}=2,33 ; \mathrm{p}=0,8014\right)$, respectivamente.
Nenhuma das amostras de água satisfez os padrões bacteriológicos de potabilidade ( $>16$ para coliformes totais e $<2,2$ para coliformes fecais) (Tabela 3).

Tabela 3- Análise bacteriológica (coliformes em NMP por 100ml) de águas coletadas em hortas com verduras contaminadas - Feira do Produtor (1996-1997).

\begin{tabular}{lcccc}
\hline Número da & Local & Tipo de & \multicolumn{2}{c}{ Coliformes } \\
\cline { 3 - 5 } barraca & coletado & água & Total & Fecal \\
\hline 41 & poço artesiano & in natura & 2,2 & $<2,2$ \\
61 & mina & in natura & 16 & $<2,2$ \\
67 & mina & in natura & $>16$ & $<2,2$ \\
88 & mina & in natura & $>16$ & $>16$ \\
102 & poço comum & in natura & $>16$ & $<2,2$
\end{tabular}

\section{DISCUSSÃO}

Os vegetais que crescem em solos poluídos podem carrear ovos de helmintos parasitas de humanos, principalmente Ascaris e Trichuris, mais resistentes às condições externas e que não requerem hospedeiros intermediários 15. Hernandes et al5 encontraram ovos de Ascaris $s p$ e de ancilostomídeos em verduras de doze hortas do município de Biritiba, um dos principais produtores do Estado de São Paulo. Mota et al9 verificaram altos níveis de enteroparasitas em hortaliças consumidas cruas na cidade de Curitiba, Paraná. Marzochi7 encontrou ovos e cistos de enteroparasitas de interesse humano em hortaliças, água e solo de cultivo na região de Ribeirão Preto.

O índice de contaminação parasitária (ovos, larvas e cistos) das hortaliças comercializadas na Feira do Produtor de Maringá foi de 16,6\%. Silva et al16 encontraram índice de 21,4\% em amostras coletadas em supermercados da zona sul e norte da cidade do Rio de Janeiro. A menor taxa encontrada em nosso trabalho poderia ser conseqüência da diminuição da manipulação tanto no acondicionamento quanto no transporte, pois o produtor passa a hortaliça diretamente ao consumidor. Portanto, sua contaminação poderia se dar principalmente durante o cultivo. Tal fato encontra suporte em Silva et al16 que observaram maiores índices de contaminação em hortaliças comercializadas em supermercados da zona norte do Rio de Janeiro, onde se verificam condições higiênico-sanitárias inferiores às da zona sul.

Os dados obtidos revelaram que a rúcula, a alface e a escarola apresentaram níveis variáveis de contaminação por protozoários e helmintos e que o agrião foi o mais contaminado. É interessante observar que as espécies parasitas aqui encontradas coincidiram com aquelas observadas por outros autores5 6101114 16. Não houve correlação entre espécie parasita e hortaliça. $\mathrm{O}$ agrião apesar de ser pouco produzido foi a hortaliça mais contaminada. De acordo com Oliveira e Germano11, a estrutura anatômica deste vegetal, por conter folhas múltiplas e separadas, permite maior fixação das formas evolutivas dos parasitas, ao contrário da alface cujas folhas são largas e justapostas.

Ao comparar-se alface lisa com a crespa, a primeira estava mais contaminada, embora isto não seja estatisticamente significante. Acredita-se que este fato se deva às condições ambientais de cultivo e não somente à estrutura anatômica do vegetal, pois quando compara-se produtores que cultivavam as duas variedades, praticamente o mesmo resultado foi encontrado.

A água utilizada no cultivo de hortaliças também é importante na disseminação de enteroparasitas 211 . Sabe-se que, principalmente na periferia das cidades, ocorre grande descarga de dejetos sobre os remansos de água. $O$ fato do agrião ser cultivado em meio aquático o tornaria mais passível de contaminação e poderia explicar os altos índices encontrados. A hipótese do esterco animal (bovino e suíno), ser também um elemento importante na contaminação de hortaliças não deve ser descartada.

O exame parasitológico de fezes mostrou que os ancilostomídeos prevaleceram sobre os outros parasitas. Este resultado concorda com trabalhos anteriores, desenvolvidos em Maringá 
e região noroeste do Paraná, onde é grande a prevalência de ancilostomíase na zona rural3 13 17. Entre os protozoários, a Entamoeba coli predominou. Esta espécie aparece também no depósito subungueal de alguns indivíduos, sendo um dos indicativos de contaminação fecal, evidenciando as baixas condições higiênicas existentes entre os produtores da região.

O encontro coincidente da mesma espécie de parasita em algumas das verduras analisadas e em indivíduos revela que o ciclo evolutivo de alguns deles (ancilostomídeos, Trichuris trichiura e Entamoeba coli) se fecha nos locais de produção das hortaliças.

Os pequenos produtores que comercializam suas verduras na feira têm suas propriedades localizadas na periferia das cidades. A análise bacteriológica das amostras de água de cinco locais que tiveram suas hortaliças contaminadas demonstra que eles recebem água contaminada por dejetos fecais, mesmo quando a amostra da água provinha de mina (Tabela 3). Os resultados aqui encontrados confirmam as observações de Marzochi7 de que a contaminação dos produtos vegetais por enteroparasitas, depende da concentração da matéria orgânica de origem fecal nas águas de irrigação provenientes da drenagem de esgotos domésticos.

Desta forma, conclui-se que mesmo as verduras comercializadas diretamente por horticultores podem transmitir protozoários e helmintos patogênicos aos consumidores.

\section{AGRADECIMENTOS}

A Ângela Cristina Benedito e Elza Custódio Pereira pelo auxílio técnico prestado no
Laboratório de Parasitologia Básica/UEM.

\section{REFERÊNCIAS BIBLIOGRÁFICAS}

1. American Public Health Association. Standard methods for the examination of water and wastewater. 19 edition, Apwa, Awwawpc, New York, 1995.

2. Cristóvão DA, laria ST, Candeias JAN. Condições sanitárias das águas de irrigação de hortas do município de São Paulo. Revista de Saúde Pública 1:3-11, 1967.

3. Falavigna DLM, Moitinho MLR, Guilherme ALF, Pupulim ART, Nerilo Sobrinho A, Fukishigue Y. Parceria Universidade Comunidade no diagnóstico e controle de parasitoses intestinais, Revista Unimar 19:649-659, 1977.

4. Gelli DS, Tachibana T, Oliveira IR, Zamboni CK, Pacheco JA, Spiteri N. Condições higiênico-sanitárias de hortaliças comercializadas na Cidade de São Paulo, SP, Brasil. Revista do Instituto. Adolfo Lutz 39:37-43, 1979.

5. Hernandes N, Cimerman B, Fernandes MFP, Ferraz CAM, Araújo AL, Silva CA. Estudo da Contaminação de Verdura no município de Curitiba Mirim. In: Anais do VI Congresso Brasileiro de Parasitologia, Belo Horizonte $\mathrm{p}$. 219, 1981.

6. Marzochi MCA. Estudo dos fatôres envolvidos na disseminação dos enteroparasitas. I-Estudo da poluição por cistos e ovos de enteroparasitas em córregos da cidade de Ribeirão Preto, São Paulo, Brasil. Revista do Instituto de Medicina Tropical de São Paulo 12:249-256, 1970.

7. Marzochi MCA. Estudo dos fatores envolvidos na disseminação dos enteroparasitas. II-Estudo da contaminação de verduras e solo de hortas na cidade de Ribeirão Preto, São Paulo, Brasil. Revista do Instituto de Medicina Tropical de São Paulo 19:148-1556, 1977.
8. Mello EB, Souza Júnior, FL, Pádua HB, Campos MS, Tanabe TH. Encontro de ovos de helmintos e de cistos de protozoários intestinais na região subungueal de crianças em idade escolar dos municípios de Diadema e de Bragança Paulista, São Paulo. Revista de Patologia Tropical 7:47-50, 1978.

9. Mota CCS, Elias A, Mikoszewska I, Vieira HRA, Pichet Neto J, Vasques RMR, Almeida A, Gaissler MS, Beatriz $\mathrm{R}$, Mota RMTCS. Condições higiênico-sanitárias de hortaliças comercializadas em Curitiba, PR. (Brasil). In: Programa e Resumos do VI Congresso Brasileiro de Ciência e Tecnologia de Alimentos, Brasília p.125, 1983.

10. Oliveira CAF, Germano PML. Estudo da ocorrência de enteroparasitas em hortaliças comercializadas na região metropolitana de São Paulo, SP, Brasil. I- Pesquisa de helmintos. Revista de Saúde Pública 26:283-289, 1992.

11. Oliveira CAF, Germano PML. Estudo da ocorrência de enteroparasitas em hortaliças comercializadas na região metropolitana de São Paulo, SP, Brasil. II- Pesquisa de Protozoários intestinais. Revista de Saúde Pública 26:332-335, 1992.

12. Pessôa S, Martins AV. Pessôa - Parasitologia Médica. Editora Guanabara Koogan, Rio de Janeiro, 1982.

13. Pupulim AR, Guilherme ALF, Falavigna DLM, Araújo SM, Fukushigue Y. Uma tentativa de orientar comunidades escolares no controle de parasitoses. Revista Brasileira de Análises Clínicas 28:130-133, 1996.

14. Rude RA, Jackson GJ, Bier JW, Sawier TK, Risty NG. Survey of fresh vegetables for nematodes, amoebae and Salmonella. Journal of the Association of Official Analys Chemical 67:613-615, 1984. 
15. Rudolfs W, Falk LL, Razotzkie RA. Contamination of vegetables grow in pollued soil. III - Field studies on Ascaris eggs. Sewages industrialized and Wastes 23:656-660, 1951.

16. Silva JP, Marzochi MCA, Camilo-Coura L, Messias AA, Marques S. Estudo da Contaminação por Enteroparasitas em hortaliças Comercializadas nos Supermercados da
Cidade do Rio de Janeiro. Revista da Sociedade Brasileira de Medicina Tropical 28:237-241, 1995.

17. Teodoro U, Casavechia MTG, Dias MLGG, Falavigna DLM, Pedroni SM, Arroio IMA. Perfil epidemiológico das parasitoses intestinais no município de Maringá, Paraná. Ciência e Cultura 40:698-702, 1988. 